\title{
Ânforas, commodities agrícolas e o ocaso do minimalismo econômico
}

Paulo Pires Duprat ${ }^{1}$

\section{Resumo}

A utilização de ânforas como método de acondicionamento foi praticada por todos os povos mediterrânicos, destacando um aspecto tecnológico comum que pode ser comprovado pela Arqueologia sob extenso recorte temporal e geográfico. Novos estudos sobre ânforas gregas e romanas estão condenando ao ocaso a visão minimalista para a economia antiga e sua noção de que apenas bens de luxo eram comercializados, haja visto que a utilização de ânforas está associada ao transporte de "commodities agrícolas". Vou apresentar algumas perspectivas oriundas do marketing design que consideram as ânforas como as primeiras embalagens de consumo (consumer package) fabricadas em larga escala, cujo projeto e design demonstram que os povos antigos praticavam uma variante de racionalismo econômico que só pode ser apreendida se analisada em seu próprio contexto.

Palavras-chave: Arqueologia; Ânforas; Commodities agrícolas; Economia antiga; Marketing design.

\section{Abstract}

The use of amphorae as packaging method was carried out by all Mediterranean peoples, highlighting a common technological aspect that can be verified by Archaeology under huge temporal and geographic scales. New studies in Greek and Roman amphorae doomed to decline the minimalist view about ancient economy and its notion that only luxury goods were traded, because the use of amphorae is linked to the transport of "agricultural commodities". I am going to present some perspectives of the marketing design that consider the amphorae as the first consumer package manufactured on large scale, whose design shows that ancient people performed a kind of economic rationalism that can be well perceived solely in its own context.

Keywords: Archaeology; Amphorae; Agricultural commodities; Ancient Economy; Marketing Design.

\section{Résumé}

L'utilisation d'amphores en guise de conditionnement était une méthode répandue parmi l'ensemble des peuples méditerranéens, mettant ainsi en évidence un aspect technologique commun que l'archéologie permet de vérifier sur une large échelle temporelle et géographique. De nouvelles recherches sur les amphores grecques et romaines tendent à faire évoluer la vision minimaliste de l'économie antique fondée sur la seule commercialisation des produits de

N

N

\footnotetext{
${ }^{1}$ Possui graduação em Biblioteconomia e Documentação (2000) e em História (2011), ambas pela UFF. É servidor público federal desde 2005 e atua como bibliotecário na FAU/UFRJ. Titulou-se como mestre em História Comparada pelo PPGHC/UFRJ em 2015, sob a orientação da Prof ${ }^{a}$ Dr. Norma Musco Mendes.
} 
luxe, dans la mesure où les amphores servaient au transport de produits agricoles. Nous présentons ici des points de vue inspirés du marketing appliqué au design, qui considèrent les amphores comme les ancêtres du packaging fabriqué à grande échelle. Leur conception et leur design montrent que les peuples anciens pratiquaient déjà une sorte de rationalisme économique, compréhensible uniquement lorsqu'il est analysé dans son contexte.

Mots-clés: Archéologie; Amphores; Produits agricoles; Économie antique; Marketing Design.

Comércio e recipientes são inseparáveis. Assim que os homens começaram a trocar bens, surgiu a necessidade de embalá-los. Independentemente do período histórico analisado, commodities são perecíveis e requerem processamento mínimo, para serem em seguida acondicionadas em recipientes capazes de suportar seu envio ao local de destino. Desta forma, pressupomos que a imensa quantidade e variedade de ânforas que circulavam no Império Romano comprovam a mobilidade e o dinamismo de sua economia. Isto inclui as atividades que envolveram redistribuição de gêneros alimentícios para o exército ou Roma, pois a alocação de recursos necessária para viabilizar esta cadeia logística fomentou a produção de excedentes, redistribuiu renda e estimulou o comércio na região, criando mercados regionais e mobilizando pessoas para o mercado de trabalho. Em suma, criou oportunidades.

$\mathrm{Na}$ Antiguidade, todos os sistemas voltados para o transporte e armazenamento de líquidos limitavam-se basicamente a três tipos de material: madeira, cerâmica e pele ${ }^{2}$. Barris são fabricados preferencialmente em carvalho por suas características ideais e sua fabricação dependia de materiais cuja disponibilidade era regionalmente restrita, além de requererem mão de obra altamente qualificada - o que cerceou a sua plena utilização por séculos ${ }^{3}$. Portanto, por muito tempo a maioria dos recipientes para líquidos (água, vinho, óleo, conservas) foram feitos de argila cozida. A argila é uma matéria-prima abundante, barata e versátil, portanto, nada mais lógico que construir contentores com este material. $\mathrm{O}$ processamento final se dava pelo cozimento em fornos alimentados a lenha ou a carvão - a fonte de energia por excelência da Antiguidade. Portanto, a ânfora se apresenta como uma

\footnotetext{
${ }^{2}$ Cantis, garrafas e contentores de couro foram usadas em escala mais restrita, em caráter pessoal ou no transporte terrestre (DORREGO, F.; CARRERA, F.; LUXÁN, M. P., 2004, p. 369; BEVAN, 2014, p. 392). Já a manufatura do vidro estava voltada para objetos de prestígio, o que inclui recipientes de pequenas dimensões para produtos de alto valor agregado, tais como cosméticos ou medicamentos.

${ }^{3}$ Embora o senso comum indique o barril como o óbvio sucessor da ânfora, trata-se de uma invenção muito antiga. Na realidade, a ânfora e o barril coexistiram por muitos séculos; a substituição total de um sistema pelo outro foi um longo e conturbado processo. Vide Bevan, 2014.
} 
solução tecnológica que se demonstra coerente e racional, face à escassa disponibilidade de matérias-primas e da limitada matriz energética dos antigos.

Há tempos os estudiosos da cultura material perceberam que as pesquisas sobre artefatos de instrumentum domesticum ${ }^{4}$ são centrais para se alcançar a história econômica da Antiguidade, oferecendo subsídios para completar as graves lacunas verificadas na documentação literária do período. As ânforas representam o mais privilegiado representante dentre os utensílios domésticos, dada a quantidade e qualidade das informações que disponibilizam para a história econômica. As peças normalmente traziam inscrições que são imprescindíveis para o estudo da economia antiga. $O$ trecho abaixo estabelece as razões:

\begin{abstract}
Objetos manufaturados muitas vezes requerem inscrições. Seja na oficina, para as marcas de controle das diferentes partes interessadas em sua fabricação, seja proprietário ou cliente; no decurso de sua utilização, para definir propriedade ou modos de uso (...). Em cada um desses casos, o arqueólogo pode questionar o autor da mensagem, seu propósito e seu destinatário. Escrever, por que e para quem? Este ramo da epigrafia, às vezes pouco explorado pelos especialistas, se apresenta como uma fonte de documentação insubstituível acerca das classes sociais que não tiveram acesso às inscrições em pedra: artesãos e seus ordinários clientes do povo miúdo (FEUGĖRE, 2004, p. 53).
\end{abstract}

Daí a importância de pesquisar os vasilhames da antiguidade, pois permite vislumbrar a trajetória histórica das classes menos favorecidas. Pouco sabemos sobre embalagens no mundo antigo porque poucos indícios restaram. As ânforas são uma notável exceção por conta de sua lenta degradação e têm sido encontrados remanescentes desses contentores por todo o Mediterrâneo e o Atlântico. Além disso, seus rastros possibilitam também delinearmos as rotas percorridas por este comércio, um caminho cujo retorno está marcado à semelhança da famosa fábula "João e Maria".

Noves fora o papel primordial da ânfora enquanto documento arqueológico, sua contribuição mais importante é que sua utilização está inextricavelmente ligada ao transporte de "commodities agrícolas" a longa distância, evidência cabal de circulação de produtos alimentícios, o que por si só confronta a noção de luxury good apresentada pela teoria

\footnotetext{
${ }^{4} \mathrm{O}$ termo instrumentum domesticum é um tanto impreciso mas encontra algum consenso entre os especialistas para referir-se à maioria dos objetos portáteis inscritos da antiguidade romana, cujas maiores expressões estão representadas pelas inscrições encontradas em ânforas, impressões em tijolos, telhas e lucernas, além dos selos e grafitos em terra sigillata (HARRIS, 1993, p. 7).
} 
primitivista de Moses Finley ${ }^{5}$, que dominou a discussão sobre a economia antiga até poucas décadas atrás.

Diversos autores se dedicaram ao estudo da economia antiga buscando transcender as teorias minimalistas. Gostaria de apresentar alguns que se utilizaram de argumentos advindos do marketing design para melhor cumprir esta tarefa. Creio que podem contribuir positivamente para o debate e os relaciono abaixo:

- a arqueóloga Virginia Grace (1901-1994) dedicou sua vida ao estudo das ânforas gregas e publicou trabalhos notáveis entre os anos 1940-1980, com ênfase para o comércio de vinho antigo, inspirando estudiosos de outras áreas, tais como historiadores, economistas, ceramistas e mineralogistas.

- Elizabeth Lyding Will (1924-2009), professora emérita de Estudos Clássicos da Universidade de Massachusetts, trabalhou com Grace nas escavações da Ágora, em Atenas, que notabilizou-se pelo trabalho sobre ânforas romanas.

- Diana Twede (1954-) é uma famosa professora da School of Packaging da Michigan State University e sua área de pesquisa é sobre a economia e desempenho das embalagens, marketing e sistemas logísticos, incluindo a história dos contêineres desde a Antiguidade até tempos modernos. Pode-se dizer que a perspectiva de Twede complementa o legado acadêmico das duas primeiras.

As três especialistas norte-americanas argumentam que há indícios da prática de marketing na utilização deste contentor, desde o período da Grécia e de Roma Clássicas, sugerindo que a antiga ânfora comercial foi não apenas um recipiente de transporte muito bem projetado, como também pode ter sido a primeira embalagem idealizada para fins de consumo. Vejamos os argumentos apresentados.

Em 1932, Grace ${ }^{6}$ filiou-se ao grupo American Excavations at the Athenian Agora in Greece, estudando cerca de 870 ânforas comerciais que foram encontradas na Ágora -

${ }^{5}$ Para maior clareza, os elementos principais da visão primitivista (minimalista) de Finley sobre a economia antiga são: ênfase na agricultura de subsistência; o papel das cidades como centros de consumo e não de produção (a cidade como parasita do setor agrário); que o comércio de longa distância se resumia a produtos de luxo e alto valor agregado; o baixo status social de comerciantes e artesãos; difusão tecnológica atrasada e carência de racionalidade econômica, exemplificada pelo baixo nível de investimento em setores não agrários (FINLEY, 1985). 
quantidade considerada suficiente para vaticinar que o local fora um mercado central. A coleção abrange artefatos que cobrem mais de mil anos de História, desde antes de 500 a. C. até o século 6 de nossa era. Os contentores são, em sua maioria, importações e chegaram a Atenas a partir de muitos lugares (GRACE, 1979, p. 13).

Em 1951, ao concluir seu doutorado, Elizabeth Will foi convidada por Grace para desenvolver estudo com as numerosas ânforas romanas que foram encontradas naquela escavação. Ela logo percebeu que os contentores podiam prover as evidências necessárias para rastrear e mapear as rotas mercantis percorridas pelos romanos e forçar uma reescritura da história econômica romana (WILL, 2000, p. 28).

A partir dos resultados de suas pesquisas, as especialistas alegam que a ânfora cumpriu a mesma função que se espera de outros tipos de embalagem hoje em dia: através delas muitos produtos alimentares foram processados e fornecidos às famílias e instituições. Foram utilizadas pelos povos mediterrânicos para transportar produtos agrícolas por milênios e estão associadas ao abastecimento dos antigos impérios grego e romano. Tal longevidade demonstra que seu design foi um sucesso incontestável ${ }^{7}$. Suas dimensões e formatos variavam de acordo com a procedência e o bem transportado; esta tipologia permite identificar seu período histórico e conectar as regiões produtoras com os destinatários dos produtos. Tal como exposto abaixo:

Pode-se considerar que foi a primeira "embalagem de consumo" produzida em escala "industrial" e seu design foi o resultado do mesmo raciocínio que utilizamos para projetar embalagens hoje em dia (TWEDE, 2002, p. 98).

A ânfora se distingue dos demais vasos cerâmicos de armazenamento principalmente por sua função econômica, idealizadas para conter um produto e possibilitar seu transporte. A base pontiaguda atribui força máxima contra impactos e solavancos em solos rígidos e

${ }^{6}$ Grace viveu e trabalhou em Atenas por toda sua vida sua vida.

7 Cabe ressaltar que a utilização em larga escala de ânforas está associado a um mundo que desconhecia as facilidades da refrigeração do mundo moderno. Num mundo sem eletricidade, a vida era muito diferente e vasos cerâmicos eram a solução por sua reconhecida propriedade em manter os alimentos frescos por mais tempo. Há diversas evidências de que os antigos buscavam maximizar estas propriedades nos porões de suas casas através da técnica de semienterramento no solo, de maneira a alcançar a mais baixa temperatura possível. Antes que alguém pense que esta é uma tecnologia que desapareceu, recente pesquisa norte-americana (The Drinks Water Book, de Colin Ingram, 2013) indicou que o filtro de barro brasileiro é o mais eficiente do mundo. $O$ assunto pode ser relacionado às ânforas pois muito desta eficiência está relacionada às propriedades da argila em manter o frescor dos produtos e inibir a proliferação de micro-organismos.

(C) Rev. Arqueologia Pública

\begin{tabular}{l|l} 
Campinas, SP & v.9
\end{tabular}

No.(11)

p.72-84

suplemento

ISSN 2237-8294 
favorecia o armazenamento e transporte. O formato oval é estruturalmente muito resistente. Os perfis de muitas ânforas formavam arco em círculo, o que distribui as cargas estáticas e dinâmicas, aumentando a superfície e dissipando as forças envolvidas.

Contando com cerca de um metro de altura em média e pesando cerca de vinte quilos quando vazia, a ânfora antiga tinha duas alças robustas em cada lado do gargalo, estrutura que servia tanto como funil para controlar o fluxo ao despejar o conteúdo quanto como suporte para possibilitar arrolhamento hermético. Em tempos romanos, a espessura de suas paredes alcançou cerca de dois centímetros, por conta da necessidade de maior robustez e resistência. O bico permitia que o pesado recipiente fosse rolado por uma pessoa a partir das alças, além de ajudar na operação de içamento e escoamento. Segundo Will (1977, p.1-2), a característica mais distintiva da ânfora antiga são suas duas alças.

As ânforas foram produzidas em grande quantidade na roda de oleiro, com secagem intermitente para adicionar rigidez. Algumas eram moldadas por etapas, a partir de peças modulares que eram ligadas posteriormente. Depois de formar o corpo e a base, os vasos eram dispostos na posição vertical e fixadas por um mandril, enquanto o pescoço e o aro eram moldados. As alças eram fixadas e moldadas na fase final da fabricação (TWEDE, 2002, p. 100; VANDIVER \& KOEHLER, 1986, p. 182-187).

A evolução no formato das ânforas desenvolveu-se em resposta à necessidade de materializar um recipiente que fosse capaz de conter a maior quantidade possível de produto sob um tamanho adequado para ser manipulado por uma única pessoa. Os oleiros mais habilidosos buscavam aprimorar as técnicas e fabricar ânforas mais eficientes, ou seja, as que continham o maior volume de produto com a menor espessura possível, sem se romperem. Algumas das ânforas mais finas foram reforçadas ao serem envolvidas por uma camada protetora de vime, semelhante aos cestos que ainda podem ser encontrados encerrando tradicionais garrafas de vinho Chianti (TWEDE, 2002, p. 99).

O formato cônico maximizava o espaço no compartimento de carga de um navio, pois eram acondicionadas em camadas superpostas num padrão semelhante ao da armazenagem de esferas ou ovos. Podiam ser reutilizadas e seu formato e tipologia variavam de acordo com os produtos transportados e da região de origem.

Devido à porosidade da cerâmica, era necessário impermeabilizá-la para o transporte de líquidos não viscosos (leia-se produtos derivados da uva). Utilizavam resinas de árvores 
típicas da região, e algumas variedades adicionavam sabor ao produto, o que era apreciado pelos antigos ${ }^{8}$.

Por toda a parte há indícios arqueológicos do reaproveitamento racional e utilitário dos contentores. Escavações nas cidades romanas, tais como Pompeia e Herculano, comprovam que as ânforas eram largamente reutilizadas, dada a carência de recipientes de estocagem nas casas, armazéns e lojas romanas. As ânforas quebradas também foram utilizadas como agregado em concreto e aplicadas na construção de paredes, pisos, portos, embarcadouros e quebra-mares. Os romanos perceberam que fixar ânforas vazias nas coberturas e nos palcos dos teatros favorecia a acústica. Há, inclusive, relatos do uso de ânforas como mísseis balísticos incendiários (lançadas através da balestra romana), ataúdes para crianças, urnas para cinzas fúnebres e decoração de túmulos (WILL, 2000, p. 30). Representam 80\% do material recuperado nos sítios romanos, sem incluir as que foram reutilizadas na construção civil. Este percentual se eleva se forem sítios subaquáticos, haja visto que em ambientes marinhos poucos materiais prevalecem além da cerâmica.

Se para os antigos as ânforas foram a solução para o comércio de exportação, para nós representam uma estratégia para contornar a escassez literária acerca de sua economia. Elas traziam inscrições (tituli picti e graffiti) cujo objetivo era transmitir informações sobre sua origem, conteúdo, tipo e período. Muitas identificavam o comerciante e dispunham de lacre hermético, visando estabelecer a confiança do usuário sobre a proveniência do produto. Estas inscrições foram deliberadas e sistemáticas; as marcas de um dado tempo e lugar são consistentes em termos de padrão e posicionamento. Embora haja alguma divergência acerca dos significados, todos os autores argumentam que a sua natureza sistemática representa em si evidência de seu papel como parte de um sistema de comércio organizado, que envolvia produtores, exportadores \& importadores e regras governamentais (GRACE, 1949,1979; WILL, 1977, 1987a, 1987b e 2000; TWEDE, 2002; TCHERNIA, 1994; LAWALL, 1995; BERNI MILLET, 2008, 2012).

Diante de tais questões, Will (1977, 1987a, 1987b e 2000) acredita que as ânforas romanas inscritas encontradas nos extremos do planeta são um indicativo do alcance do

\footnotetext{
8 A resina também era uma commodity largamente comercializada na Antiguidade e possuía características aromatizantes e flavorizantes muito apreciadas. Plínio (N. H., 12.72) e Plutarco (Quaestiones Conviviales, 5. 3) escreveram sobre o tema.
} 
comércio romano e que isto pode ser considerado uma espécie de capitalismo ${ }^{9}$. Devido ao potencial polêmico de tal afirmação, é indispensável enfatizar que a solução de Weber ${ }^{10}$ para a famosa questão sobre estágios de desenvolvimento difere significativamente da de Marx, que previa etapas obrigatoriamente sucessivas para a economia. Para Weber, a esquematização das estruturas sócio-econômicas comparativas não exclui a possibilidade do surgimento de tipos de capitalismo anteriores ao modo burguês. Desviar-me-ei desta celeuma, mas cabe enfatizar que, em minha opinião, a evidência arqueológica direta da movimentação de produtos já atingiu massa crítica suficiente para refutar cabalmente as teorias reducionistas acerca da economia antiga, ao menos no que se refere ao período romano alto-imperial. $\mathrm{E}$ talvez tais diretrizes possam ser aplicadas para algumas fases do comércio grego de vinho.

Pesquisas há muito consolidadas sobre as ânforas hispânicas de azeite Dressel 20 destinadas a Roma demonstraram a presença de inscrição padrão de quatro ou cinco elementos pintados no pescoço, entre as alças. O primeiro exprime um valor que provavelmente é a tara da ânfora vazia. O segundo indicaria o peso bruto (cheio). O terceiro é o nome do navicularis ou expedidor. A quarta é uma série de símbolos que seriam a marca dos órgãos governamentais fiscalizadores, contendo o tipo do produto e uma indicação de propriedade original do bem, além do nome da cidade onde o controle foi realizado. A quinta parece ter sido alguma instrução específica para armazenamento (TWEDE, 2002, p. 105). Em suma, tal como o comprador de hoje, o consumidor da Antiguidade dispunha de dados e podia escolher o produto que desejasse, com a qualidade e na quantidade que estivesse disposto a pagar.

Cabe observar que os dados dispostos contém boa parte dos elementos necessários para satisfazer a nossa própria lei de rotulagem de produtos: consta uma espécie de etiqueta disponibilizando informações de peso e capacidade do contentor, bem como o transportador, a origem do produto, propriedade e responsabilidades fiscais, além de instruções de armazenamento. Não difere muito dos rótulos dos produtos que compramos todos os dias nos mercados $^{11}$.

${ }^{9}$ Ela expõe o motivo da relutância da comunidade acadêmica em admitir tal possibilidade: (...) por muitos anos, historiadores marxistas negaram que houvesse comércio motivado pelo lucro no período clássico. Porquê? Porque, em 1867, Karl Marx escreveu em seu Das Kapital que a era capitalista só começou a partir do séc. XVI (WILL, 2000, p. 28).

${ }_{10}$ Tal como o autor expõe em seu livro $A$ ética protestante e o espírito do capitalismo, de 1905.

11 Seguindo tendência mundial, apenas recentemente a Agência Nacional de Vigilância Sanitária (Anvisa) determinou que fossem dispostas nos produtos informações adicionais acerca de sua 
O cerne da questão é que as alterações na forma e marcações verificadas no decorrer dos séculos refletem mudanças na identidade da marca. A hipótese apresentada é que estas variações indicam evolução nas estruturas econômicas. Se mais informações são transmitidas, tais como local de fabrico, produtor, a natureza e o valor do conteúdo, outros sistemas não são necessários para a transmissão da informação e isto reduz o custo da unidade, e por consequência, os custos das transações ${ }^{12}$; ou seja, o pacote se torna um "vendedor silencioso". Em todo caso, o comportamento econômico é afetado.

A transmissão de informação através da embalagem sempre fez parte de um sistema maior. Da mesma forma que os sistemas atuais de identificação, as marcações na ânfora precisavam ser facilmente decodificadas para fins de confrontação com os documentos de embarque e venda - e mesmo iletrados poderiam apreender os significados básicos das inscrições, tal como ocorre atualmente. Da mesma maneira que os ícones das marcas corporativas fazem sentido pra nós hoje, o sistema simbólico dos tituli picti e grafitos eram inteligíveis e foram apreciados pelos consumidores antigos, pois ofereciam informações vitais para viabilizar a comercialização de produtos que podiam tornar sua vida mais fácil e agradável. Esta é uma das principais razões pelas quais a ânfora pode ser considerada um "pacote de consumo" (LAWALL, 1995, 1998 apud TWEDE, 2002, 105-7). Ademais, podemos dizer que este sistema pode ser considerado um exemplo perfeito de racionalismo econômico da Antiguidade.

Grace enfatiza que analisar os padrões de desenvolvimento no design da ânfora a partir de espécimes bem datados representam a chave para alcançarmos os resultados. A interconexão entre os nomes dos produtores e das autoridades governamentais que são citadas nos selos preenchem e consolidam as sequências de um quebra-cabeça que já está sendo montado. Em suas palavras:

Para o historiador econômico, agora estamos em condições de oferecer informações sobre o comércio de vinho com base em números impressionantes e datas confiáveis. Os estudos em terra serão cada vez complementados pelos mergulhadores. À medida em que as técnicas progridem, eles avançam ao longo dos litorais do mundo antigo e mapeiam as cargas perdidas que vão delinear para nós os caminhos do comércio antigo (GRACE, 1979, p. 31).

composição, valores nutricionais e se estão isentos de nutrientes específicos, tais como açúcar, sódio, lactose ou glúten.

${ }_{12}^{2}$ O raciocínio está de acordo com a teoria de custos de transação, de Douglass North (1993 e 1994).

(C) Rev. Arqueologia Pública

\begin{tabular}{l|l|} 
Campinas, SP & v.9
\end{tabular}

No.(11)

p.72-84 suplemento

ISSN 2237-8294 
Este artefato, a ânfora, cujo projeto revelou notável grau de sofisticação e eficiência, cumpriu com êxito todas as funções de uma embalagem moderna: proteção, utilidade e comunicação. Pode ser considerada uma obra-prima da engenharia de embalagens, diante da tecnologia disponível na época. Seu nível de desempenho foi elevado, haja visto que foi utilizada por milênios. Diante de tais questóes, Twede (2002, p. 107) lança um desafio: poderíamos nos perguntar se alguma de nossas formas contemporâneas de embalagem vai sobreviver por tanto tempo.

\section{Bibliografia:}

BERNI MILLET, Piero. Autopsie du Timbre sur amphore romaine. In: M.E. Fuchs, R. Sylvestre, C.S. Heidenreich (dir.). Inscriptions mineures: nouveautes et reflexions. Actes du premier colloque Ductus (19-20 juin 2008, Université de Lausanne), 2012, p. 152-163.

Epigrafía anfórica de la Bética: nuevas formas de análisis. Barcelona:

Real Academia de la Historia, 2008.

BEVAN, Andrew. Mediterranean containerization. Current Anthropology, Vol. 55, n , 2014, p. 387-418.

CARDOSO, Ciro Flamarion. Existiu uma "economia Romana"? In: Phoînix, v. 17, n. 1, 2011, p. 15-36.

DORREGO, F.; CARRERA, F.; LUXÁN, M. P. Investigations on Roman amphorae sealing systems. In: Materials and Structures / Matériaux et Constructions, vol. 37, Jun 2004, p. 369374.

FEUGÈRE, Michel. L'instrumentum, support d'écrit. Gallia, Editions du CNRS, 61, 2004, p.5365.

FINLEY, M.I. A economia antiga. Porto: Afrontamento, 1986.

FUNARI, P.P.A. ; GARRAFFONI, Renata Senna. Economia romana no início do Principado. In: SILVA, Gilvan V.; MENDES, Norma M. (Eds.). Repensando o Império Romano: perspectiva socioeconômica, política e cultural. Rio de Janeiro: Mauad; Vitória: EDUFES, 2006, p. 53-63. 
FUNARI, P.P.A. Arqueologia. São Paulo: Contexto, 2003. . Considerações sobre a contribuição da Arqueologia da Bética para o estudo da economia romana. Arq. Etn. Supl., São Paulo, no 18, 2014, p. 19-27..

O comércio interprovincial e a natureza das trocas econômicas no Alto Império romano: as evidências do azeite bético na Bretanha. In: PHOÎNIX, Sette Letras, 2000, p. 295-311.

GREENE, Kevin. Technological innovation and economic progress in the ancient world: M. I. Finley reconsidered. The Economic History Review, New Series, v. 53, no. 1, 2000, p. 29-59.

GRACE, Virginia R. Amphoras and the ancient wine trade. Athens: American School of Classical Studies, 1979.

Stamped Amphora Handles Found in 1931-1932. Hesperia, 1934, p.

197-310. Disponível em: <www.ascsa.edu.gr/pdf/uploads/hesperia/146478.pdf>.

Standard Pottery Containers of the Ancient Greek World. Hesperia

Supplements, v. 8, Commemorative Studies in Honor of Theodore Leslie Shear, 1949, p.175189.

HARRIS, W. V. Concerning this book. In: W. V. Harris (ed.). The Inscribed Economy. Production and distribution in the Roman empire in the light of instrumentum domesticum. (Journal of Roman Archaeology Supplement 6). Ann Arbor: Journal of Roman Archaeology, 1993, p.7-9.

HOPKINS, Keith. Taxes and Trade in the Roman Empire, 200 b. C. - 200 a. C. In: Journal of Roman Study, 1980, p.101-125.

Rome, taxes, rents and trade. In: SCHEIDEL, Walter; REDEN, Sitta von (ed.). The Ancient Economy. New York: Routledge, 2002, p. 190-230.

LAWALL, Mark Lewis. Transport amphoras and trademarks: imports to Athens and economic diversity in the fifth century B.C. (Ph.D thesis, University of Michigan). Michigan, University of Michigan, 1995.

MATTINGLY, David J. Imperial economy. In: A Companion to the Roman Empire. David S. Potter (Ed.). Malden, MA: Blackwell, 2006, p. 283-297.

v.9

p.72-84


NORTH, Douglass. Economic performance through time. The American Economic Review, vol. 84, №. 3, 1994, pp. 359-368. Disponível em: <http://www.jstor.org/stable/2118057>. Acesso em: 27/06/2013, 09:07.

Institutions and economic performance. In: Rationality, institutions, and economic methodology - Gustafsson, Knudsen, and Maki (eds.), 2005, c1993, p. 246-265.

POLANYI, Karl. The great transformation: the political and economic origins of our time. Boston: Beacon Press, 1957.

SALLER, R. Framing the debate over growth in the ancient economy. In: SCHEIDEL, W.; VON REDEN, S. (Ed.) "The ancient economy”. New York: Routledge, 2002, p. 251-269.

SCHEIDEL, W.; VON REDEN, S. (eds.) The ancient economy. New York: Routledge, 2002.

TWEDE, Diana. Baskets, barrels and boxes: the history of wooden shipping containers. 22nd IAPRI Symposium Proceedings. Campinas, Brazil: Centro de Tecnologia de Embalagem. May 22-24th, 2005.

Commercial amphoras: the first consumer packages? The Journal of Macromarketing 22 (1), 2002, p. 98-108.

WILL, Elizabeth Lyding. Shipping amphoras as economic indicators. Rei Cretariae Romanae Fautorum Acta XXV-XXVI, 1987, p. 71-77.

. The Ancient Commercial Amphora. Archaeology 30, 1977, p. 264278.

. The Roman Amphora: Learning from Storage Jars. Archaeology Odyssey, Jan-Feb, 2000, p. 26-35.

. The Roman amphoras. In: The Roman Port and fishery of Cosa, edited by A. M. McCann, Joanne Bourgeois, Elaine K. Gazda, John Peter Oleson, and Elizabeth Lyding Will. Princeton, NJ: Princeton University Press, 1987, p. 171-220.

. The Sestius amphoras: a reappraisal. Journal of Field Archaeology, 6, 1979, p. 339-350. Disponível em: <http://www.promare.org/wpcontent/uploads/2012/06/Will-1979-The-Sestius-Amphoras.pdf>. 
